\title{
Power Quality Enhancement by Unified Power Quality Conditioner Using ANN with Hysteresis Control
}

\author{
RVD Rama Rao \\ Associate Professor \\ Dept of EEE, Narasaropeta \\ Engineering College Narasaraopet, \\ Guntur Dt, A.P,India
}

\author{
Dr.Subhransu.Sekhar.Dash \\ Professor \& Head, Dept of EEE, \\ College of Engineering, \\ SRM University \\ Chennai, India
}

\begin{abstract}
The quality of the Electrical power is effected by many factors like harmonic contamination, due to non-linear loads, such as large thyristor power converters, rectifiers, voltage and current flickering due to arc in arc furnaces, sag and swell due to the switching of the loads etc. One of the many solutions is the use of a combined system of shunt and active series filters like unified power quality conditioner (UPQC) This device combines a shunt active filter together with a series active filter in a backto-back configuration, to simultaneously compensate the supply voltage and the load current or to mitigate any type of voltage and current fluctuations and power factor correction in a power distribution network. The present work study the compensation principle and different control strategies used here are based on PI \& ANN controller of the UPQC in detail. The control strategies are modeled using MATLAB/SIMULINK. The simulation results are listed in comparison of different control strategies and for the verification of results.
\end{abstract}

\section{Keywords}

active power filter; artificial neural network-ANN; harmonics; power quality; unified power quality conditioner.

\section{INTRODUCTION}

The power electronic devices due to their inherent non-linearity draw harmonic and reactive power from the supply. In three phase systems, they could also cause unbalance and draw excessive neutral currents. The injected harmonics, reactive power burden, unbalance, and excessive neutral currents cause low system efficiency and poor power factor. In addition to this, the power system is subjected to various transients like voltage sags, swells, flickers etc.[1]-[2] These transients would affect the voltage at distribution levels. Excessive reactive power of loads would increase the generating capacity of generating stations and increase the transmission losses in lines. Hence supply of reactive power at the load ends becomes essential.[3-5].Power Quality (PQ) mainly deals with issues like maintaining a fixed voltage at the Point of Common Coupling (PCC) for various distribution voltage levels irrespective of voltage fluctuations, maintaining near unity power factor power drawn from the supply, blocking of voltage and current unbalance from passing upwards from various distribution levels, reduction of voltage and current harmonics in the system.[6-7].

This paper presents a novel method for derivation of compensation signals in UPQC using neural network with hysteresis control. The performance of the system is verified by extensive simulation on Matlab/SPS environment.

\section{SYSTEM CONFIGURATION}

Basic block diagram of UPQC is shown in Figure.1, where as the overall control circuit is shown in the Figure.2. The voltage at PCC may be or may not be distorted depending on the other nonlinear loads connected at PCC. Here the assumption of the voltage at PCC is distorted. Two voltage source inverters are connected back to back, sharing a common dc link.[8-10]

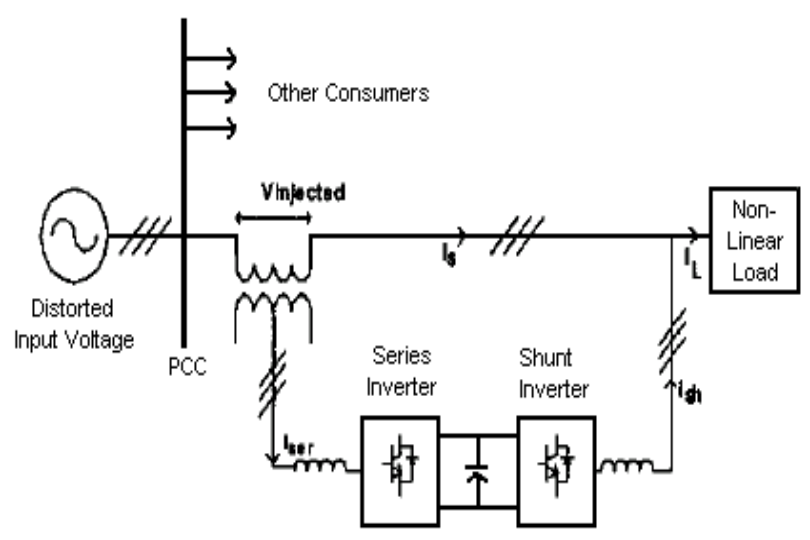

Figure.1 Basic Block Diagram of UPQC

One inverter is connected parallel with the load. It acts as shunt APF, helps in compensating load harmonic current as well as to maintain de link voltage at constant level. The second inverter is connected in series with utility voltage by using series transformers and helps in maintaining the load voltage sinusoidal.[11-12]

As for the shunt active filter of the UPQC it is represented by $\frac{v_{d v}}{2} u_{2}$ with $l_{s h}$ as the first order low-pass interfacing filter and $r_{s h}$ as the losses of the shunt VSI. $\frac{v_{d e}}{2} u_{2}$ represents the switched voltage across the shunt VSI output of the UPQC. The injection current of the shunt active filter is denoted by $i_{i n g}$ both $u_{1}$ and $u_{2}$ take the value of either -1 or 1 depending on the switching signal of the hysteresis control. 


\section{OVERALL CONTROL CIRCUIT CONFIGURATION OF UPQC}

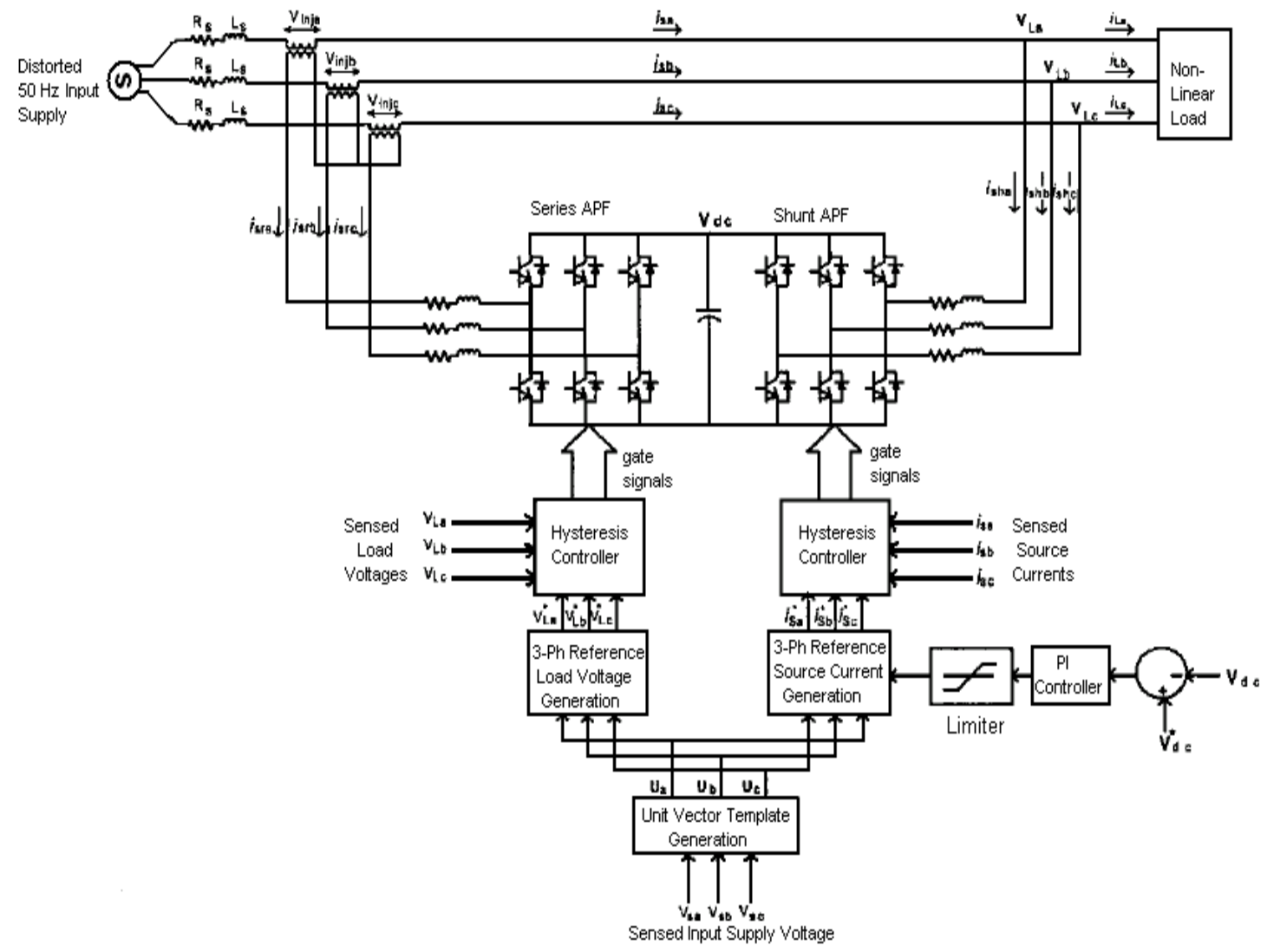

Figure.2 Overall Control Circuit Configuration of UPQC

In Figure. 2 the instantaneous current of the nonlinear load $\boldsymbol{i}_{\boldsymbol{L}}$ is expanded into 3 terms. The first term $i_{L J p}$ is the load Reference currents and voltages are generated using Phase Locked Loop (PLL).The control strategy is based on the extraction of Unit Vector Templates from the distorted input supply. These templates will be then equivalent to pure sinusoidal signal with unity (p.u.) amplitude. The extraction of unit vector templates is

$$
\left.\begin{array}{c}
\mathbf{U}_{\mathrm{a}}=\sin (\mathbf{w t}) \\
\mathbf{U}_{\mathrm{b}}=\sin (\mathbf{w t}-\mathbf{1 2 0}) \\
\mathbf{U}_{\mathrm{c}}=\sin (\mathbf{w t}+\mathbf{1 2 0})
\end{array}\right\}
$$

Multiplying the peak amplitude of fundamental input voltage with unit vector templates of equation (1) gives the reference load voltage signals,

$$
\mathrm{V}^{*}{ }_{\mathrm{abc}}=\mathrm{V}_{\mathrm{m}} \cdot \mathrm{U}_{\mathrm{abc}}
$$

The error generated is then taken to a hysteresis controller to generate the required gate signals for series APF. The unit vector template can be applied for shunt

Figure.3 Extraction of Unit Vector Templates and 3- $\Phi$ Reference Voltages shown in the Figure.3.The unit vector templates are

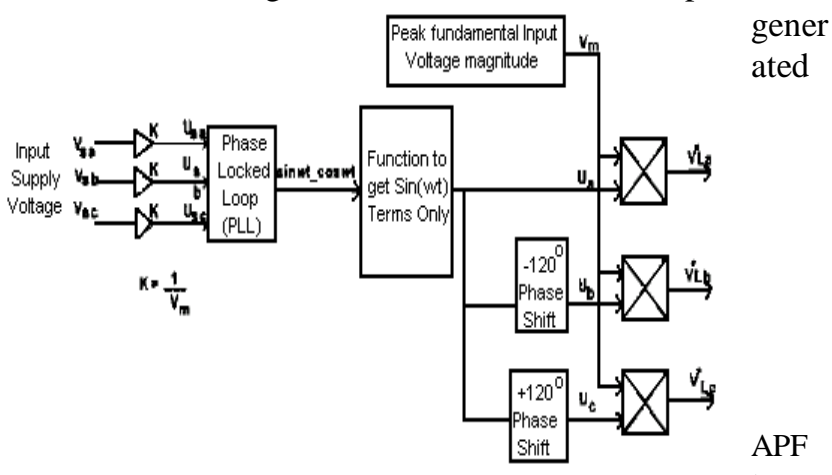

to

compensate the harmonic current generated by non-linear load. The shunt APF is used to compensate for current harmonics as well as to maintain the dc link voltage at constant level [13-14]. To achieve the above mentioned task the dc link voltage is sensed and compared with the reference dc link voltage. A PI controller then processes the error. The output signal from PI controller is multiplied with unit vector templates of equation (1) giving reference source current signals. The source current must be equal to this reference signal. In order to follow this reference current signal, the 3-phase source currents are sensed and compared with reference current signals. The error generated is then processed by a hysteresis current controller with suitable 
band, generating gating signals for shunt APF. The UPQC uses two back-to-back connected three phase VSI's sharing a common $\mathrm{dc}$ bus. The hysteresis controller is used here to control the switching of the both VSI's.

\section{CONTROL STRATEGY OF UPQC}

UPQC consists of series compensator and shunt compensator. The shunt compensator is controlled by a PWM current control algorithm, while the series converter is controlled by a PWM voltage control algorithm. According to the adopted control scheme, these two parts of UPQC have different functions as follows:

\subsection{Static Shunt Compensator}

In Figure. 2 the instantaneous current of the nonlinear load $i_{L}$ is expanded into 3 terms. The first term $i_{\text {LJp }}$ is the load

functions sent from PLL (Phase Locked Loop) in accordance with equation.(3)

$$
\mathrm{I}_{\mathrm{Ldq} 0}=\mathrm{T}_{\mathrm{abc}}{ }^{\mathrm{dq} 0} \mathrm{i}_{\mathrm{Labc}}
$$

By this transform, the fundamental positive sequence components are transformed into dc Quantities in $\mathrm{d}$ and $\mathrm{q}$ axes, which can easily be extracted by low-pass, filter (LPF).

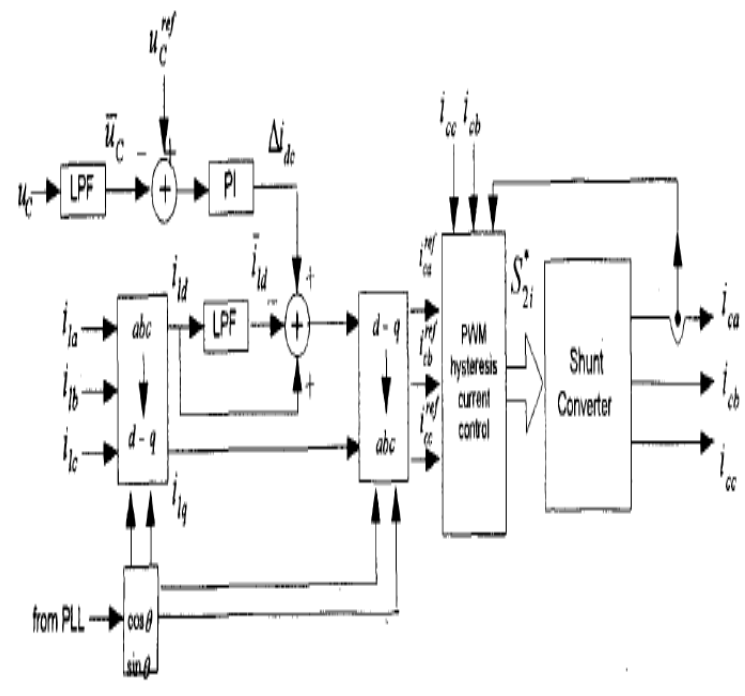

Figure.4 Control of the shunt Converter of the UPQC

All harmonic components are transformed into ac quantities with a fundamental frequency shift.

$$
I_{L q}=\bar{i}_{L q}+\tilde{i}_{L q}
$$

Since $i_{L}=i_{s}+i_{c}$
This means there is no harmonics and reactive components in the system currents. The switching loss can cause the dc link capacitor voltage to decrease. Other disturbances, such as unbalances and sudden variations of loads can also cause this voltage to fluctuate. In order to avoid this, in Figure 4. a PI controller is used. The input of the PI controller is the error between the actual capacitor voltage and the desired value, its output then added to the reference current component in the daxis to form a new

\subsection{Static Series Compensator}

The system side voltage may contain negative-zero-sequence as well as harmonics components which need to be eliminated by the series compensator [15-16]. The control of the series compensator is shown in Figure.5. The system voltages are detected then transformed into synchronous dq-0 reference frame using equation (6).

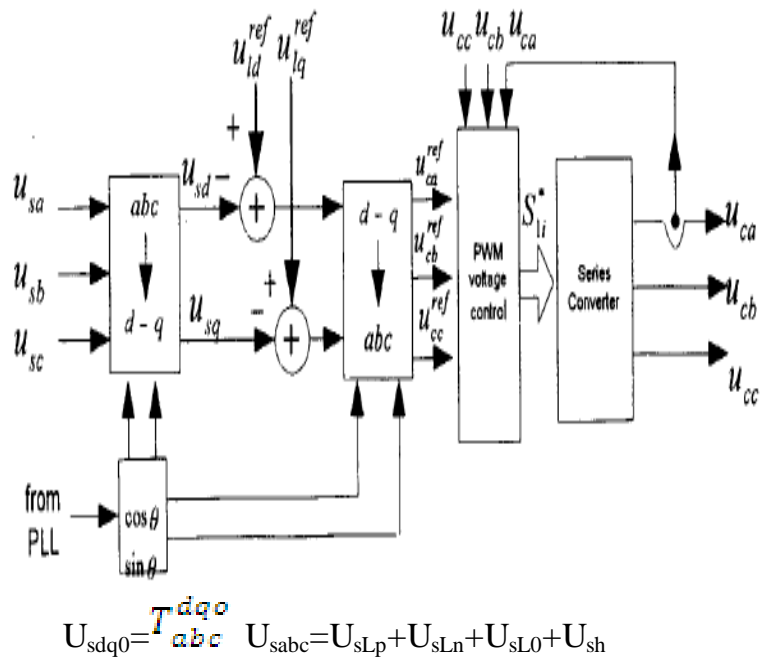

Figure.5 Control block diagram of the series converter of the UPQC

\section{DESIGNING \& TRAINING OF ANN}

An ANN is essentially a cluster of suitably interconnected nonlinear elements of very simple form that possess the ability of learning and adaptation. These networks are characterised by their topology, the way in which they communicate with their environment, the manner in which they are trained and their ability to process information [18]. Their ease of use, inherent reliability and fault tolerance has made ANNs a viable medium for control. An alternative to fuzzy controllers in many cases, neural controllers share the need to replace hard controllers with intelligent controllers in order to increase control quality [19]. A feed forward neural network works as compensation signal generator. This network is designed with three layers. The input layer with seven neurons, the hidden layer with 21 and the output 
layer with 3 neurons. Activation functions chosen are tan sigmoidal and pure linear in the hidden and output layers respectively.

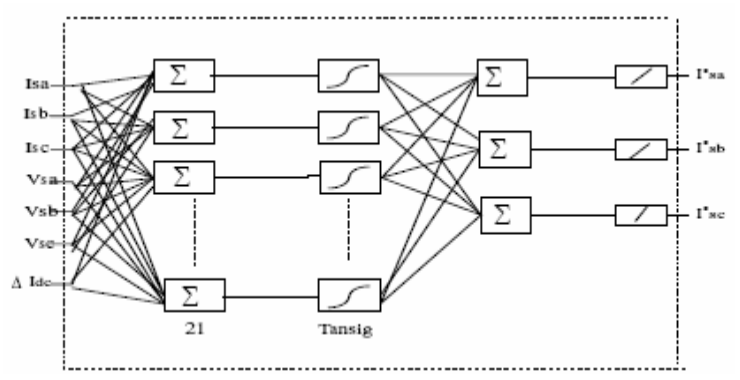

Figure.6 Network Topology of ANN

The training algorithm used is Levenberg Marquardt back propagation (LMBP). The Matlab programming of ANN training is as given below:

net $=$ newff $(\operatorname{minmax}(\mathrm{P}),[7,21,3]$,

\{'tansig','tansig','purelin'\},'trainlm');

net.trainParam. show $=50$;

net.trainParam.lr $=.05$;

net.trainParam.mc $=0.95$;

net.trainParam.1r_inc $=1.9$;

net.trainParam.lr_dec $=0.15$;

net.trainParam .epochs $=1000$;

net.trainParam.goal = 1e-6;

[net,tr] =train $($ net, $\mathrm{P}, \mathrm{T})$;

$\mathrm{a}=\operatorname{sim}($ net, $\mathrm{P})$;

gensim(net,-1);

The compensator output depends on input and its evolution. The chosen configuration has seven inputs three each for reference load voltage and source current respectively, and one for output of error (PI) controller. The neural network trained for outputting fundamental reference currents [20]. The signals thus obtained are compared in a hystersis band current controller to give switching signals. The block diagram of ANN compensator is as shown in Figure 7.

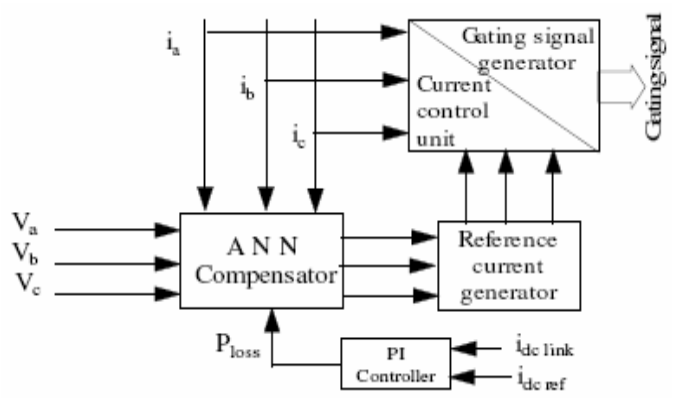

Figure.7 Block diagram of ANN-based compensator

\section{SIMULATION RESULTS}

The harmonic content of input and output of the Bridge converter are shown in Figure 8. (three phase voltages) and Figure 9. (three phase currents).
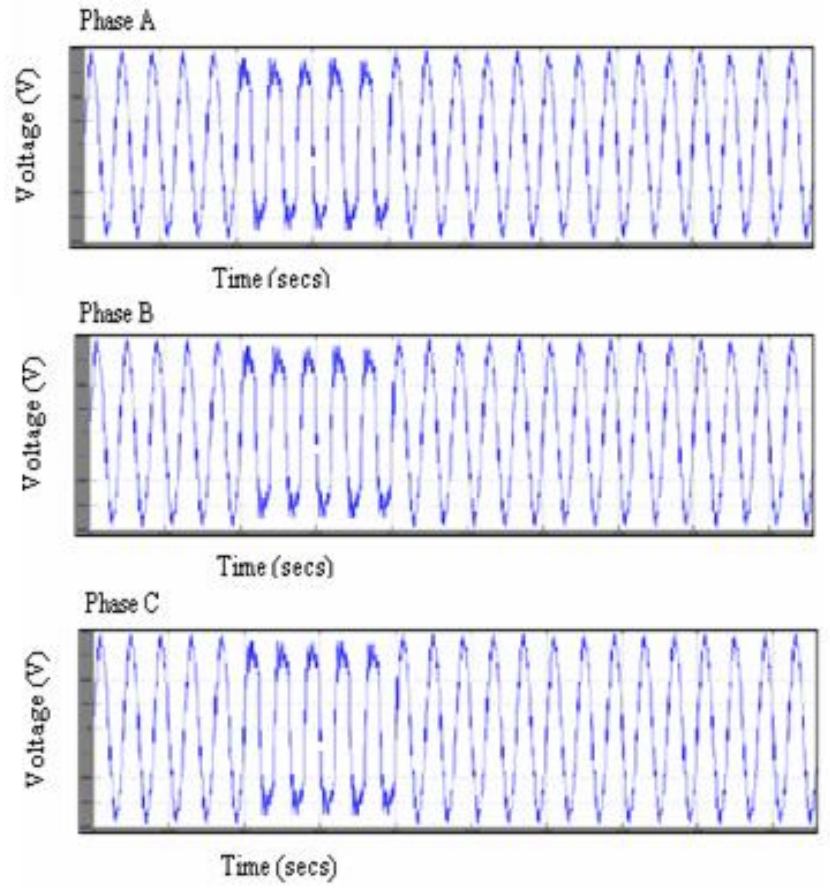

Figure.8 Wave form of 3-Ф load voltages without UPQC for Phase A, Phase B and Phase C
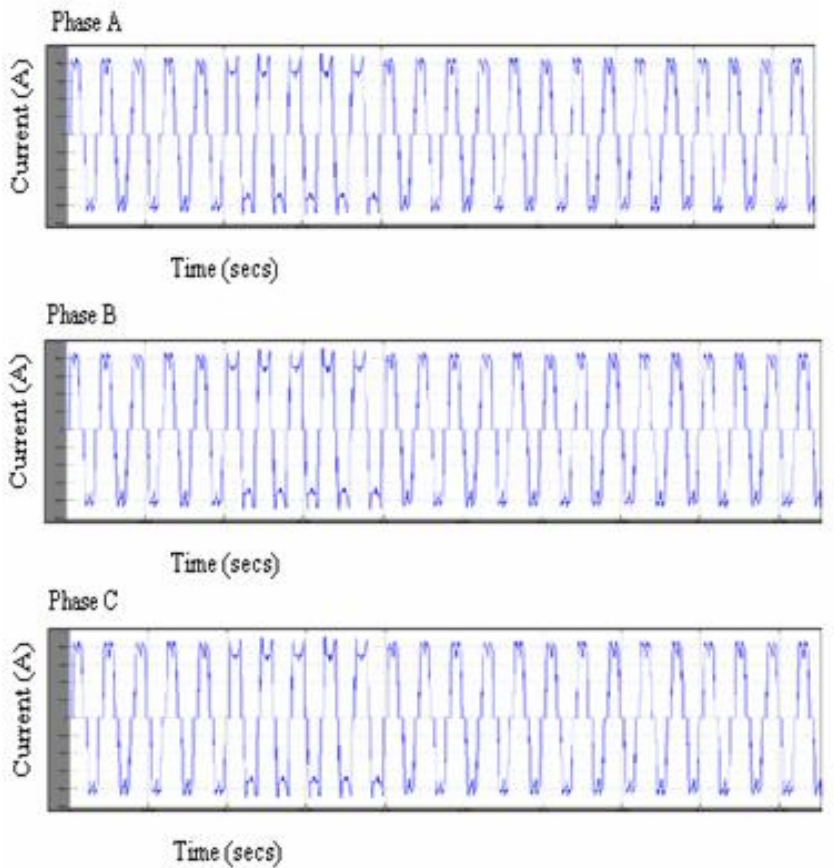

Figure. 9 Wave form of 3- $\Phi$ Source currents without UPQC for Phase A, Phase B and Phase C

To verify the operating performance of the proposed UPQC, a 3$\Phi$ electrical system, a PLL extraction circuit with hysteresis controlled UPQC is simulated using MATLAB software. Figure 10. shows the unit vector templates generated by using proposed control technique. 


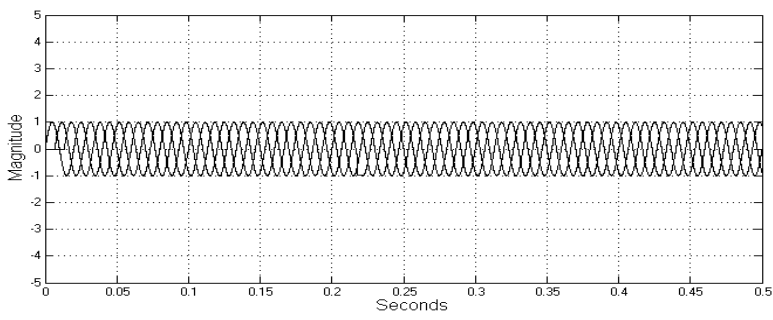

Figure. 10 Unit Vector Templates output 3 phase voltages

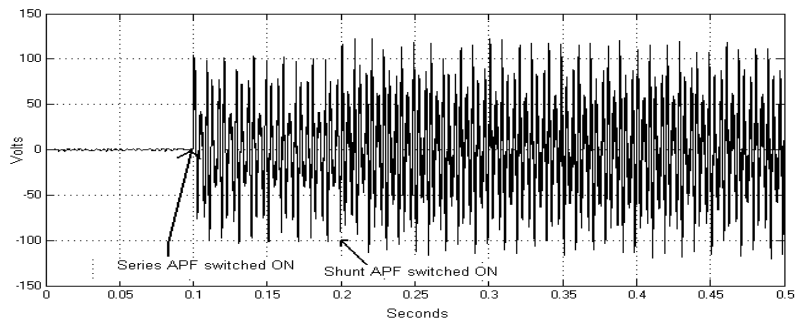

Figure. 11 Wave forms of Voltage Injected by Series APF

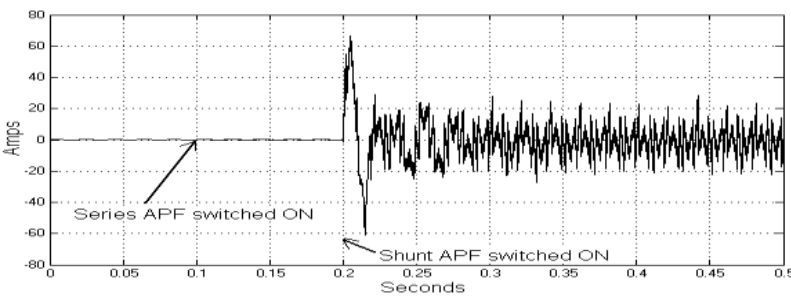

Figure. 12 Wave forms of Current Injected by Shunt APF

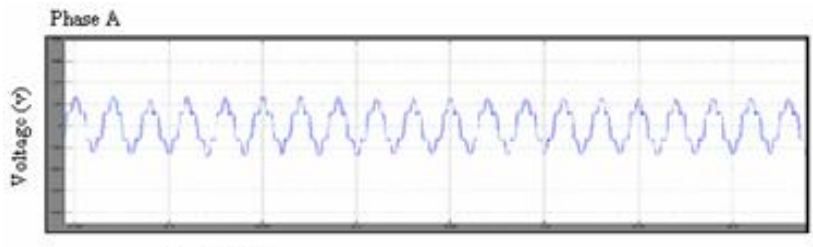

Time (secs)

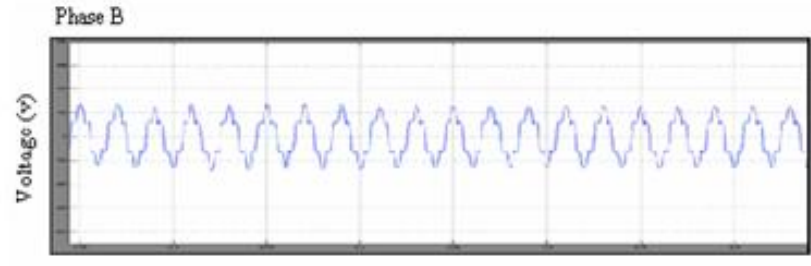

Time (secs)

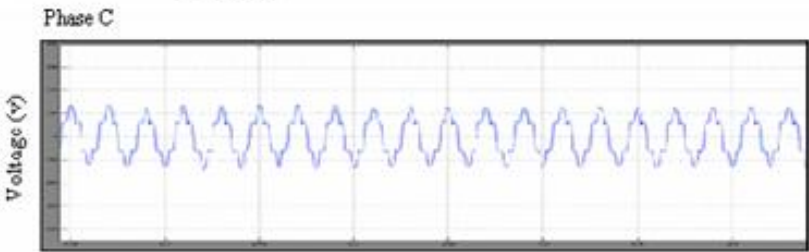

Time (secs)

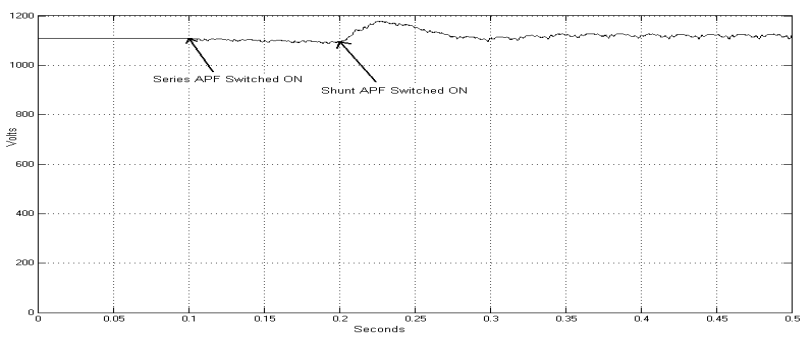

Figure. 13 Wave forms of D.C Link Voltage

The simulation results are shown in the Figure 14. load voltages \& Figure 15. Source currents of both the series and shunt APF's and they are put into the operation at different time instant.

Figure. 14 Wave forms of 3- $\Phi$ Load Voltages with UPQC for Phase A, Phase B and Phase C
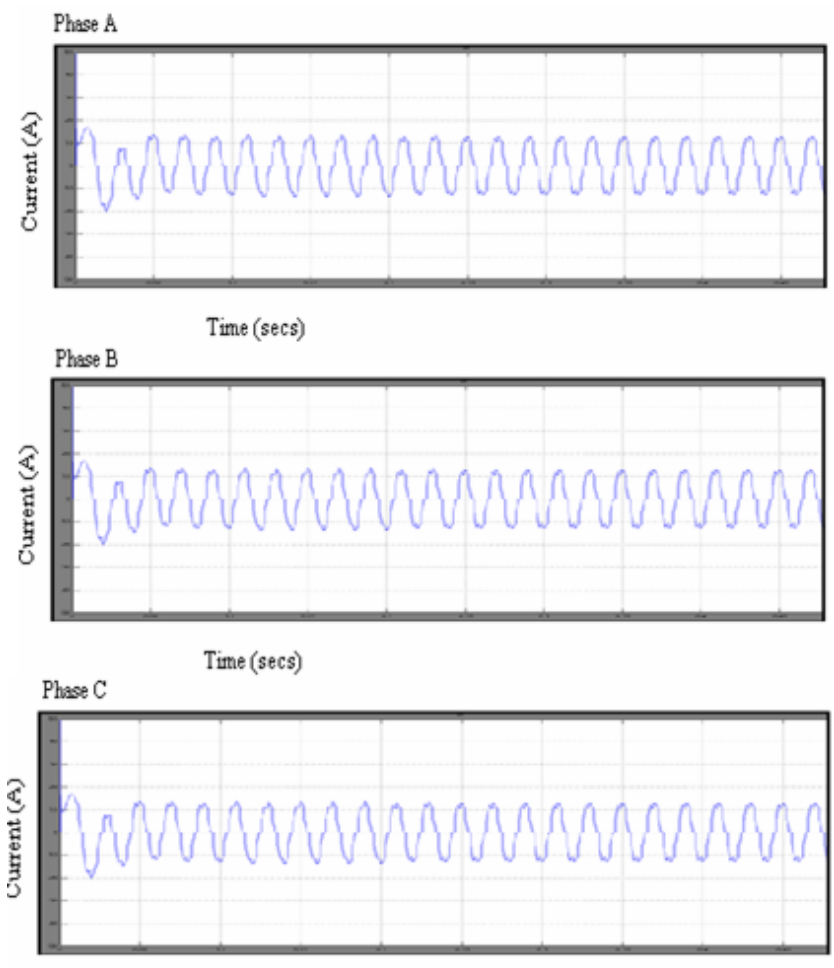

Time (secs)

Figure. 15 Wave forms of 3- $\Phi$ Source Currents with UPQC for Phase A, Phase B and Phase C 
Table.1 Voltage and current harmonics (THD's) of UPQC

\begin{tabular}{|l|l|l|l|l|l|l|}
\hline Order of harmonics & $\begin{array}{l}\text { WITHOUT } \\
\text { UPQC } \\
\text { utility side } \\
\text { voltage }\end{array}$ & $\begin{array}{l}\text { WITHOUT } \\
\text { UPQC } \\
\text { utility side } \\
\text { current }\end{array}$ & $\begin{array}{l}\text { UPQC } \\
\text { with PI } \\
\text { controller } \\
\text { utility } \\
\text { side } \\
\text { voltage }\end{array}$ & $\begin{array}{l}\text { UPQC with } \\
\text { PI controller } \\
\text { utility side } \\
\text { current }\end{array}$ & $\begin{array}{l}\text { UPQC } \\
\text { with ANN } \\
\text { controller } \\
\text { utility } \\
\text { voltage }\end{array}$ & $\begin{array}{l}\text { UPQC } \\
\text { ANN } \\
\text { controller } \\
\text { Utility } \\
\text { current } \\
\text { side }\end{array}$ \\
\hline $3^{\text {rd }} \& 5^{\text {th }}$ & 4.2 & 24.2 & 2.99 & 2.99 & 1.2 & 1.2 \\
\hline $5^{\text {th }} \& 7^{\text {th }}$ & 4.2 & 24.6 & 3.42 & 3.42 & 1.19 & 1.19 \\
\hline $7^{\text {th }} \& 9^{\text {th }}$ & 4.2 & 24.6 & 2.18 & 2.18 & 1.3 & 1.3 \\
\hline
\end{tabular}

The shunt APF is put into the operation at instant ' $0.2 \mathrm{sec}$ '. Within the very short time period the shunt APF maintained the dc link voltage at constant level as shown in Figure.13. In addition to this the shunt APF also helps in compensating the current harmonics generated by the nonlinear load.

It is evident that before time ' $0.1 \mathrm{sec}$ ', as load voltage is distorted, As soon as the series APF put in to operation at ' $0.1 \mathrm{sec}$ ' the load current profile is also improved. Before time ' $0.2 \mathrm{sec}$ ', the source current is equal to load current. But after time ' $0.2 \mathrm{sec}$ ', when shunt APF starts maintaining dc link voltage it injects the compensating current in such a way that the source current becomes sinusoidal .Current injected by the shunt APF is shown in Figure.12. model of the UPQC has been developed with different shunt controllers (PI and ANN) and simulated results.

\section{REFERENCES}

[1] L.H.Tey,P.L.So and Y.C.Chu,Unified power Quality Conditionar for improveing power Quality Using ANN with Hysterisis Control, IEEE Tran. Power Electronics, vol. 9, no.3, May 1994, pp. 1441-1446.

[2] Hirofumi Akagi, Trends in Active Power Line Conditioners, IEEE Tran. Power Electronics, vol. 9, no.3, May 1994, pp. 263-268.

[3] Janko Nastran, Rafael Cajhen, Matija Seliger, and Peter Jereb, Active Power Filter for Nonlinear AC Loads, IEEE Trans. Power Electronics, vol.9, no.1, Jan. 1994, pp. 92-96.

[4] E. Destobbeleer and L.Protin, On the Detection of Load Active Currents for Active Filter Control, IEEE Trans. Power Electronics, vol. 11, no.6, Nov. 1996, pp. 768-775.

[5] Mauricio Aredes, Jorgen Hafner, and Klemens Hermann, Three-Phase Four-Wire Shunt Active Filter Control Strategies, IEEE Trans. Power Electronics, vol.12, no.2, Mar. 1997, pp. 311-318.

[6] [6] Hideaki Fujita and Hirofumi Akagi, the Unified Power Quality Conditioner: The Integration of Series- and Shunt- Active Filters, IEEE Tran. Power Electronics, vol. 13, no.2, Mar. 1998, pp.315-322.

\section{CONCLUSIONS}

The closed loop control schemes of direct current control, for the proposed UPQC have been described. A suitable mathematical have been described which establishes the fact that in both the cases the compensation is done but the response of ANN controller is faster and the THD is minimum for the both the voltage and current which is evident from the plots and comparison Table 1..Proposed model for the UPQC is to compensate input voltage harmonics and current harmonics caused by non-linear load. The work can be extended to compensate the supply voltage and load current imperfections such as sags, swells, interruptions, voltage imbalance, flicker, and current unbalance. Proposed UPQC can be implemented using simple analog hardware, because it is having PLL and Hysteresis blocks.

[7] Fang Zheng Peng, George W. Ott Jr., and Donald J.Adams, "Harmonic and Reactive Power Compensation Based on the Generalized Instantaneous Reactive Power

Theory for Three-Phase Four-Wire Systems, IEEE Trans,Power Electronics, vol.13, no.6, Nov. 1998, pp. 1174-1181.

[8] Kishore Chatterjee, B.G. Fernandes, and Gopal K.Dubey, An Instantaneous Reactiv Volt Ampere Compensator and Harmonic Suppressor System, IEEE Trans. Power Electronics,vol. 14, no.2, Mar.1999, pp. 381-392.

[9] Po-Tai Cheng, Subhashish Bhattacharya, and Deepak D. Divan, Line Harmonics Reduction in High-Power Systems Using Square-Wave Inverters-Based Dominant Harmonic Active Filter, IEEE Trans. Power Electronics, vol. 14, no.2, Mar. 1999, pp. 265-272.

[10] hyh-Jier Huang and Jinn-Chang Wu, A Control Algorithm for Three-Phase Three-Wired Active Power Filters Under Nonideal Mains Voltages, IEEE Trans. Power Electronics, vol. 14, no. 4, Jul. 1999, pp. 753-760.

[11] Ambrish Chandra, Bhim Singh, B.N.Singh, and Kamal Al-Haddad, An Improved Control Algorithm of Shunt Active Filter for Voltage Regulation, Harmonic Elimination, Power-factor Correction, and Balancing of 
Nonlinear loads, IEEE Trans. Power Electronics, vol. 15, no.3, May 2000, pp. 495-507.

[12] Moleykutty George, Modeling and simulation of a current controlled three-phase shunt active power filter using MATLAB/PSB, AIUB Journal of Science and Engineering, vol. 3, no.1, Aug. 2004 issue, pp. 11-18.

[13] M. George, C.L. Seen, Modeling and control of zerosequence current of parallel three-phase converters using Matlab/power system blockset, IEEE Power Systems Conf. and Exp. 2004, PSCE 2004, vol. 3, pp. 1440-1443.

[14] Hyosung Kim, Sang-Joon Lee, and Seung-Ki Sul, A calculation for the compensation voltages in dynamic voltage restorers by use of PQR power theory, 19th Annual IEEE Applied PowerElectronics Conf. and Expo. 2004, APEC '04, vol. 1, pp. 573-579.

[15] J. G. Nielsen, M. Newman, H. Nielsen, and F. Blaabjerg, Control and testing of a dynamic voltage restorer (DVR) at medium voltage level, IEEE Trans. on Power Electronics, vol. 19, issue 3, May 2004, pp. 806-813.

[16] E. K. K. Sng, S. S. Choi, and D. M. Vilathgamuwa, Analysis of series compensation and DC-link voltage controls of a transformerless self-charging dynamic voltage restorer, IEEE Trans. Power Delivery, vol. 19, issue 3,Jul. 2004, pp. 1511-1518.

[17] M. J. Newman, D. G. Holmes, J. G. Nielsen and F. Blaabjerg, A dynamic voltage restorer (DVR) with selective harmonic compensation at medium voltage level, IEEE Trans. Ind. Application, vol. 41, issue 6, Nov.-Dec. 2005, pp. 1744-1753.

[18] Elmitwally, A., Abdelkader, S. and EL-Kateb, M. (2000) 'Neural network controlled three-phase four-wire shunt active power filter', IEE Proc.,-Gener. Trans. Distr., March, Vol. 147, No. 2
[19] Jayalaxmi, A., Tulasiram Das, G., Uma Rao, K. and Rayudu, K. (2006) 'Comparison of PI and ANN control strategies of unified shunt series compensator', Proceedings of IEEE Power India Conference, April, p.7

[20] K. Vadirajacharya,P. Agarwal and H.O. Gupta,"Performance evaluation of CSI-based unified power quality conditioner using artificial neural network",Int. J. Power Electronics, Vol. 1, No. 1, 2008

Mr.R.V.D.Rama Rao received A.M.I.E graduation from I.E(India),Calcutta, India. The M.Tech Degree from J.N.T.U, Ananthapur.(with specialization in Power and Industrial Drives) in 1997and 2005 respectively. He is presently pursuing part-time Ph.D in J.N.T.U, Hyderabad, Andhra Pradesh. His areas of interests include Power Quality by Custom Power Devices , controllers like Conventional controllers, A.I controlling Techniques, Fuzzy controllers, Neuro Controller Neuro-Fuzzy controllers, Power Electronics and Drives.

Dr.Subhransu Sekhar Dash received A.M.I.E graduation from I.E (India), Calcutta, India. The M.E Degree from U.C.E, Burla, Orissa, India,.(with specialization in Power Systems) and the $\mathrm{Ph} . \mathrm{D}$ degree in Electrical Engineering from Anna University College of Engineering, Guindy, Chennai-25 in 1994, 1996 and 2006 respectively. He has published more number of Papers in National and International reputed Journals. He is presently working as Professor in SRM Engineering College, SRM University, Chennai, India and His areas of interests include FACTS, Power System operation, Control \& Stability, Power Electronics \& Drives and Intelligent controlling Techniques. 